\title{
Pictures of Synthetic Biology
}

\section{A reflective discussion of the representation of Synthetic Biology (SB) in the German-language media and by SB experts}

\author{
Amelie Cserer · Alexandra Seiringer
}

Received: 14 May 2009/Revised: 2 July 2009/Accepted: 31 July 2009

(C) The Author(s) 2009. This article is published with open access at Springerlink.com

\begin{abstract}
This article is concerned with the representation of Synthetic Biology in the media and by biotechnology experts. An analysis was made of German-language media articles published between 2004 and 2008, and interviews with biotechnology-experts at the Synthetic Biology conference SB 3.0 in Zurich 2007. The results have been reflected in terms of the definition of Synthetic Biology, applications of Synthetic Biology and the perspectives of opportunities and risks. In the media, Synthetic Biology is represented as a new scientific field of biology with an engineering-like thinking, while the scientists interviewed mostly define Synthetic Biology as contrary to nature and the natural system. Media articles present Synthetic Biology broadly with positive potential and inform the publics less about the potential risks than about the benefits of Synthetic Biology. In contrast, the experts interviewed reflect more on the risks than the opportunities of Synthetic Biology. Both used metaphors to describe Synthetic Biology and its aspects.
\end{abstract}

Keywords Synthetic Biology $\cdot$ Representation · Media $\cdot$ Experts

Synthetic Biology is a very new and innovative specialisation within the science of genetic technology. Synthetic Biology aims at analysing molecular entities, like physics and chemistry, but also to copy, to shape and to create

A. Cserer $(\square)$

Institute of Technology Assessment (ITA),

Austrian Academy of Sciences, Vienna, Austria

e-mail: amy.cser@gmx.at

\author{
A. Seiringer \\ dialog $<>$ gentechnik, Vienna, Austria
}

"natural" entities. The possibility of creating artificial organisms moves the basics of life reproduction into the reach of technological production.

Hampel and Pfenning (1999) suggested that the German population on average valued genetic engineering more negatively than other new technologies such as telecommunication, computer technology and solar technology. The results showed that the public was very ambivalent towards genetic engineering and that the identification of real applications polarized public attitudes.

The development of technology in post-modern societies has not only technological or scientific legitimacy (Hampel and Renn 1999). Interactive models of social and technological influences show how different powers in real action and in symbolic action contribute to the cost and profit balance, which feeds into decisions for or against innovative technology (Latour 2002; Bourdieu 1970).

In the last few years, applications of genetic engineering such as DNA testing in forensic medicine, have been acknowledged by the public. But are there any applications and products of Synthetic Biology that are already represented seriously within the media? How is Synthetic Biology represented in the media at all? How do metaphors show the characteristics of Synthetic Biology? How do the metaphors recommend a specific gendering? What about the experts who research and develop SB-artefacts? Do experts have an ambivalent opinion towards the technological progress of Synthetic Biology or do experts also have polarizing opinions?

\section{Aim of the reflective discussion}

The following article shows results of a media analysis of the German-language media, which were reflected by the 
findings of an analysis of expert interviews. The media analysis and the analysis of SB expert interviews are results of two research projects. The two projects have been part of an interdisciplinary research project with the aim to analyse the communication of Synthetic Biology (COSY). The interdisciplinary project "COSY" took place from 2008 to 2009 in the frame of the Austrian Gen-AU and ELSA II program (www.gen-au.at). This article can also be seen as an example, how results of different research streams of an interdisciplinary project can be reflected to each other.

Definitions of Synthetic Biology, applications of Synthetic Biology and the perspectives of opportunities and risks are reflected by statements from the media and interviews with biotechnology experts. A special focus will be on the rhetorical use of metaphors, which also enables to discover a gendering of Synthetic Biology.

The goal of this paper is a kind of snapshot of the representation of Synthetic Biology in the media and by SBexperts and the reflection of these two pictures to each other. Our aim was to identify similarities and highlight differences.

The results should help to establish principles of knowledge transfer to intensify a realistic discourse between science and society.

\section{Methodology}

\section{Definition of Synthetic Biology}

Synthetic Biology aims to 1. engineer and study biological systems that do not exist as such in nature, and 2. use this approach for (i) achieving better understanding of life processes, (ii) generating and assembling functional modular components, (iii) developing novel applications or processes. (Boldt et al. 2009 citing Tessy 2008)

Media analysis

"How do the German-language media include the new scientific field of Synthetic Biology in their coverage, and how is it framed?" This research question structured the monitoring and analysis of media articles in German. ${ }^{1}$

Methodologically the theory of qualitative-quantitative content analysis was used. Within this method, a codesheet and codebook were developed and a list of criteria compiled. The codebook includes formal criteria (e.g.

\footnotetext{
${ }^{1}$ Within the budget of the COSY-project and because of the more or less national focus of the project's concept, only articles in German are in the sample of the media analysis.
}

length, type of media, date of publication, etc.) and content criteria (e.g. topic, subfield of Synthetic Biology, ${ }^{2}$ potential applications of Synthetic Biology, ${ }^{3}$ benefits/risks of SB, use of metaphors, etc.).

All the texts were analyzed by means of these criteria. Various aspects, such as the benefit/risk ratio and the use of metaphors, were identified in the articles and their correlation checked.

The sample of relevant media articles was the result of a systematic search in the APAdefacto-media-database ${ }^{4}$ for keywords like "synthetische biologie", "minimalorganismus", "künstliches Leben", "synthetische DNA", etc. Additionally Google Alerts were used to monitor the coverage of Synthetic Biology in the media. The selected search term was "synthetische biologie". The sample included articles published in Austrian, German or Swiss print media (daily press and magazines), popular sciencenewsletters and -journals, selected broadcast stations and on relevant German-language online-media.

For the media analysis, articles published between January 2004 and December 2008 were collected. ${ }^{5}$

\section{Analysis of expert interviews}

The expert interviews took place at the Synthetic Biology conference SB 3.0 in Zurich 2007. The first SB conference has been the SB 1.0 conference initiated in 2004 by the synthetic biotechnologist Drew Endy at MIT. The conference since developed to be the most prominent international platform for the communication of Synthetic Biology.

Fifteen scientists who participated at the conference as prominent representatives of Synthetic Biology were chosen and interviewed by Markus Schmidt, the project leader of the EU funded internet-platform "Synbiosafe", 6 which is concerned with safety and ethical aspects of Synthetic Biology. The decision, whom to choose as a representative scientist of SB, was based on the experience of Markus Schmidt. The aim was to interview European and American scientists, who have an international reputation as an expert within the Synthetic Biology development. Every

\footnotetext{
${ }^{2}$ Subfields of Synthetic Biology are mentioned in the definition of Synthetic Biology above.

${ }^{3}$ Partly distinguished and partly are improvements of classical biotechnology applications.

4 APAdefacto is one of the largest media-database in Europe including 220 data-sources and more than 90 million documents (http://www.apa-defacto.at/).

5 These sample period was fixed in the concept of the COSY-project: media analysis should take place since the year of the first international conference of synthetic biology in 2004 and during the whole project duration.

${ }^{6}$ SYNBIOSAFE (2009), www.synbiosafe.eu.
} 
scientist, who was asked for an interview joined it. There was no drop out quote. The interview was based on four main topics, which were framed by the questions:

1. What's your name? Where do you work? What do you do? What is your special interest?

2. How would you define Synthetic Biology?

3. What kind of applications do you think could be reached within 5-10 years?

4. What do you think are the benefits of Synthetic Biology? What do you think are the risks of Synthetic Biology?

Every expert got the same question. Each interview was held in English language.

The experts showed two categories of expertise: 8 "biotechnologists", who work as biotechnology researchers and engineers in SB laboratories, and 7 scientists, who observe the development of Synthetic Biology with backgrounds in political science, history, law and social science. The two categories are named "biotechnologist" and "observer". These labels are chosen to be very openly in the sense of meaning. "Biotechnologist" means therefore that the expert is a professional, working as researcher and scientist in a laboratory concerned with Synthetic Biology. The label "observer" means that the expert is a professional, who investigates to analyse the circumstances of the development, the present streams and the forecasted potential of Synthetic Biology. The "observer" works in governmental or non-governmental organisations investigating especially on the societal, economic and political aspects of inventions and innovations of Synthetic Biology.

The experts are internationally known for their thriving impact into the development of SB. As "biotechnologist" concerned with SB engineering and research have been interviewed: Victor de Lorenzo, Vitor A. P. M. d. Santos, Scott Mohr, Piet Herdewijn, Georg M. Church, Drew Endy, Sven Panke and Philippe Marlière. As "observer" investigating in the social aspects of SB have been interviewed: Ken Oye, Gautam Makunda, Malcom Dando, Clara Sattler d. Sousa e. Brito, Jim Thomas, Huib de Vriend and Christian Krassnig.

The distribution by nationality was 9 Europeans to 6 U.S. Americans. The distribution of experts by work affiliation was balanced with 7 scientists employed at university and 7 scientists working in a non-governmental organisation. The distribution of sex was out of balance by 14 men to one woman. ${ }^{7}$

\footnotetext{
$\overline{7}$ The minor representation of women prevents an analysis of sex related statements. Statements can therefore only be analyzed by their gender references to the symbolic level of cultural values and norms.
}

\section{Results}

The media analysis included 182 articles on the topic of Synthetic Biology. The number of articles increased five fold from 11 articles published in 2004 to 91 articles published in 2008.

In most of the articles 'synthetic RNA or life' (34), successful creation of the synthetic bacterium by the Craig J. Venter (31), 'metabolic engineering' (17) and the 'successful transplantation of a synthetic bacterial chromosome' (15) were the main topics. The successful creation of the synthetic DNA of a bacterium by the Craig J. VenterInstitute ('Mycoplasma genitalium') was the second most frequent main topic, all published in 2008 alone (Fig. 1).

The expert interviews were analysed with the help of "Grounded Theory" (Glaser and Strauss 1998). Grounded Theory is a qualitative method to gain by categorizing, analysing, summarizing and referencing a close to the source theory.

Three categories were inductively defined: "definitions of SB", "applications and artefacts of SB" and "moral judgement of risk and opportunities of SB" by the experts. A fourth category was introduced with the aim of analysing the use of metaphors. The analysis of metaphorical language included especially a focus on references to gendered semantics.

The metaphor in this sense is a reference to something the "consumer" of the "new" information is already familiar with. The metaphorical language brings meaning to the "new" circumstances and artefacts. This is not a fixed or single process, neither exists only one framework of interpretation (Hall 1997; Dahinden 2006). The described entities, the character and the functions of Synthetic Biology get "personhood" by metaphorical language (Martin 1991). This is a personhood, which is not gender neutral. As Jane Caputi analysed, a metaphor is able to create consciousness and feeling about the unknown. The metaphor sets up connections by linking a "product with some positive symbol or association already held by the viewers, to induce resonance" (Caputi 1988, p. 491).

\section{Definitions of Synthetic Biology}

\section{In the media}

Almost every article dealing with Synthetic Biology used metaphors such as "biological engineer", "playing Lego" or "re-designer of life". The phrases also very often related to the terms "machines", "factories", "computer engineering" and "creation" (Fig. 2).

„Wie Ingenieure aus genormten Komponenten Maschinen oder Computer konstruieren, wollen die Pioniere dieser Disziplin aus biologischen Grundbausteinen neue 

articles over the years
Fig. 1 Main topics of the

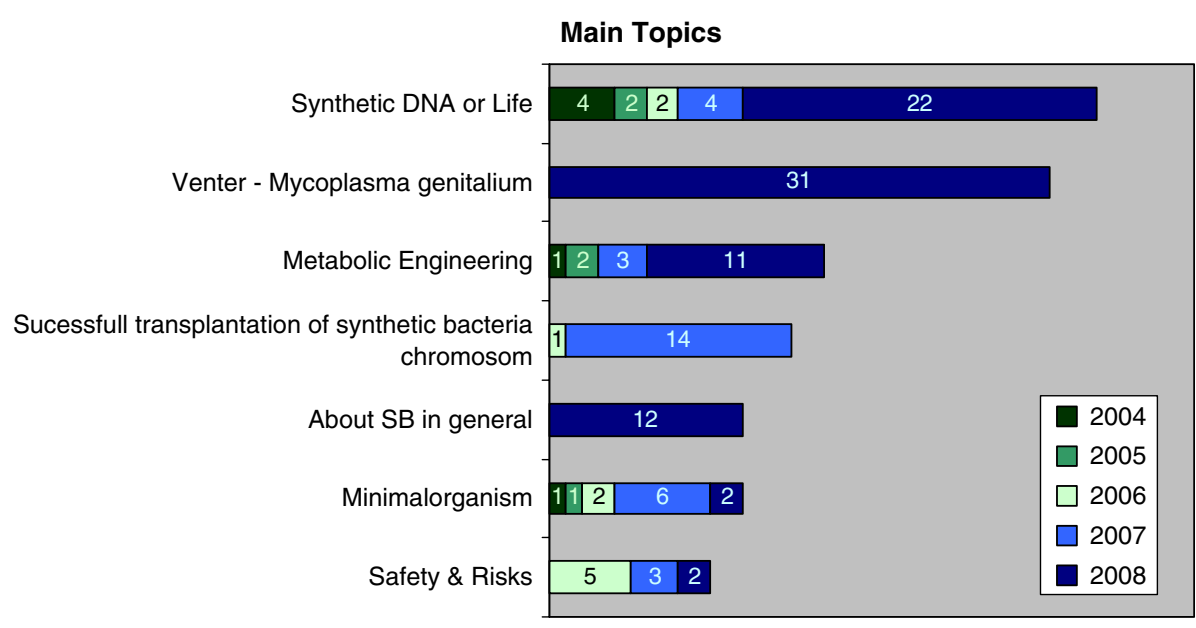

Fig. 2 Total number of articles with the most-used metaphors

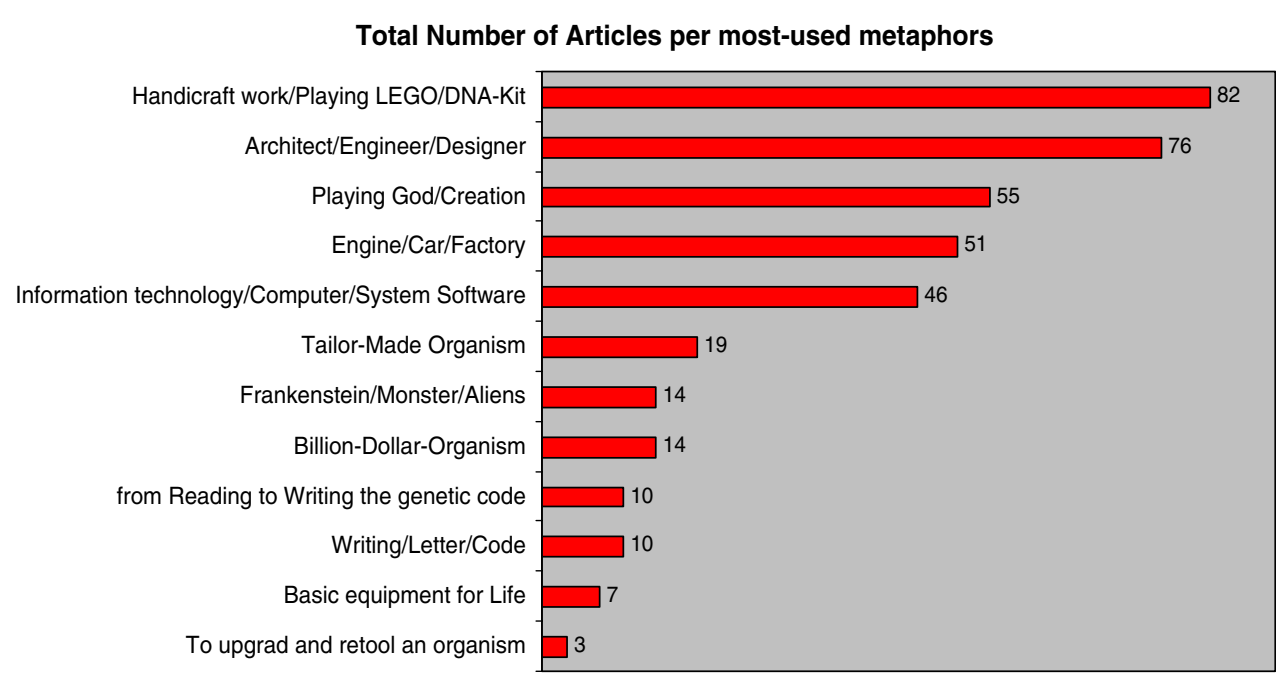

„Biomaschinen“ entwickeln,....“ (Neue Züricher Zeitung; 23.8.06)

In the same way as engineers design machines and computers with standardized components, the pioneers in this field want to develop new "bio machines" with biological bricks, ...

„Bunten Legosteinen gleich werden dabei genetische Bauteile eingesetzt, um Bakterien wunschgemäß besonderen Eigenschaften zu verleihen." (FAZ, 27.1.08)

Like coloured Lego bricks, genetic components are used to add desired and special features to bacteria.

„Das ist wie ein biologischer Bastelkasten“ (TechnologyReview, 16.12.08)

It's like a biological DIY kit

„Projekt Genesis - Biologen wiederholen die Schöpfung im Reagenzglas“ (Die Zeit, 16.2.06)
Project Genesis-Biologists repeat creation in vitro

Not every article dealing with Synthetic Biology used the term "Synthetische Biologie". Especially in 2006 and also in 2007 most of the articles used this term, but in 2004, 2005 and again in 2008 the relation between the number of media articles using and not using this term was balanced.

\section{Expert interviews}

The majority of biotechnologists described the newness of Synthetic Biology in terms of its engineering work culture. This was linguistically identified with words like "engineering", "parts", "assembly" or "devices". The biotechnologist Sven Panke for example spoke of turning biotechnology into "true engineering". "I would define Synthetic Biology as any activity that is ready to convert biotechnology into a true engineering discipline. In the sense that the true engineering discipline is based on things 
like modular design, identifiable systems boundaries and for example the separation of design and manufacturing."

The analysis of the expert interviews also showed that the definition of the new character of "Synthetic Biology" in terms of its engineering work culture implies an oppositional characteristic to "nature". An example of this kind of definition was the summarizing sentence by Piet Herdewijn: "I would say that everything that you can make with biological devices, which is new, which doesn't exist in nature, (...) I consider it Synthetic Biology."

A common aspect of all answers from the observing researchers from the fields of political, historical and social sciences was that the aims and the productivity of Synthetic Biology is contrary to nature and the natural system. Synthetic Biology was seen to produce an artificial nature, a man-made nature, which is in particular a product of engineering culture. In this sense, the "observers" share the same definition of the new character of SB with the "biotechnologists". The descriptions of Synthetic Biology claiming an oppositional characteristic to nature ranged from "unnatural" processes, to new life forms, to artificial organisms and the creation of a parallel world. The observing scientist Ken Oye sharpened the distrust in the artificiality of SB products by the example of the name "Synthetic Biology" itself. The name would increase the already negative reactions of people who believe in the beauty and divine character of nature.

The experts used metaphors to describe the scientific character of Synthetic Biology. The metaphors referred to the development of the Internet, to the garage and factory as production sites, to the cell phone, to the desktop printer, to the magnifying glass, to the parachute, to the car and the LEGO toy for children. Victor de Lorenzo illustrated this, for example: "I would argue that we are, I would say in the "game" state. So our Synthetic Biology community is playing with developing parts, developing bacteria that flash, that turn green, that turn red, that behave in a particular way." And the biotechnologist George M. Church, who introduced the metaphor of a "car": "Synthetic Biology is an attempt to do engineering on biology. True engineering of a sort where you have parts, like you have parts you use to make a car."

The distribution of metaphors showed that the majority of the eight scientists who work in an SB laboratory used metaphors to explain characteristics of Synthetic Biology, but only two of the seven observing experts used a metaphor to explain a specific problem of Synthetic Biology, like Malcom Dando. He introduced the "silver bullet" as a metaphorical artefact and practice to secure the development of Synthetic Biology. We have "to have a serious discussion about what is the best form of intervention at those particular points. And not to expect, as people argued here at this conference, not to expect that there is any silver bullet."
Artefacts and applications of Synthetic Biology

\section{In the media}

Most of the applications mentioned in the articles were still more or less trends for the future, like the production of fuel using bacteria, solutions for the energy crisis or the breakdown of pollutants.

„Die synthetische Biologie will neue Geschöpfe erschaffen - und sie für die Menschheit arbeiten lassen. Sie soll Medikamente oder Werkstoffe hervorbringen, die die Natur nicht oder nur widerwillig hergibt: wahlweise Krebs bekämpfen, schädliche Stoffe aufspüren und vernichten, Energieträger wie Wasserstoff produzieren oder Dinge hervorbringen, an die wir noch gar nicht denken." (TechnologyReview; 21.6.06)

Synthetic Biology wants to create new creaturesand make them work for mankind. They are to generate pharmaceuticals and raw materials which nature is reluctant to make: battling against cancer, detecting and destroying pollutants, producing energy sources like hydrogen or creating things we have not even thought about.

More articles containing real artefacts of Synthetic Biology appeared at the end of 2007 and in 2008, e.g.:

„Das Vorzeigeprojekt der synthetischen Biologie ist ein Bakterium, das den Malaria-Wirkstoff Artemisinin herstellt“ (Tagesanzeiger-Sonntagszeitung, 24.06.2007, Seite: 72)

The Synthetic Biology showcase project is a bacterium that produces the anti-malaria agent Artemisinin.

„Preiswertes Bioethanol durch synthetische Hefe“ (APA-Journal Energie; 19.11.07)

Less expensive bio ethanol using synthetic yeast

„Anti-Krebs-Bier im Werden“ (Wissenschaft-Aktuell; 17.10.08)

Anti-Cancer Beer in progress

\section{Expert interviews}

The expert Jim Thomas illustrated the possible impacts as follows: "This is not one specific area. It's not just food. It's not just drug. It's not just textiles. This is going to affect every single area of production in society. Basely it's turning organisms, where there is a microbe or later on plants and animals into factories that can make the basic stuff we need for life."

This is a common task of the statements by scientists whose role are to observe the development of Synthetic 
Biology. The description provides an overall vision of the possibilities of SB-artefacts, without naming a specific, realized product. The majority of observing experts did not speak about SB artefacts actually realised. Only the experts who work in laboratories referred to current inventions like Artemisinin or DNT detecting bacteria. ${ }^{8}$

The experts forecasted a positive commercial prosperity for future Synthetic Biology products. They spoke in this context of the commercial potential for example of innovative medicine, which would be cheaper using artificial production and therefore affordable for more and poorer people. Synthetic Biology would replace the production of expensive medicine.

\section{Opportunities and risks}

\section{In the media}

The media articles informed the public less about the potential risks than the benefits of Synthetic Biology. In the case of negative aspects, the focus of information turned on biological weapons or common aspects like misuse and the unknown risks of technology.

„Wissenschaftler können heute ganze DNS-Stränge synthetisieren und komplizierte molekulare "Maschinen“ zusammensetzen. Doch diese neuartigen Möglichkeiten im Labor werfen allerlei Fragen auf: könnten Terroristen oder angriffslustige Staaten mit Hilfe der Biotechnologie tödliche Viren wie den Pockenerreger im Reagenzglas nachbauen? Oder gar Krankheiten am Computer entwerfen, die tödlicher als die Vogelgrippe sind?" (TechnologyReview; 6.6.06)

Nowadays scientists are able to synthesize entire DNA strands and to compose complex molecular "machines". But these new possibilities in labs pose all kinds of questions: Could terrorists or aggressive states replicate a lethal virus like the smallpox-virus in vitro with the help of biotechnology? Or even computer-designed diseases more fatal than bird flu?

„Terroristen könnten versucht sein, sich aus dem Werkzeugkasten der synthetischen Biologie zu bedienen und Monster-Mikroben herzustellen“ (der Spiegel 33/2006)

Terrorists could be tempted to use the Synthetic

Biology toolbox to create monster-microbes

Benefits like ecological and commercial potential, progress and new research development, solutions for the energy crisis, health problems and for "the hunger of the

\footnotetext{
8 "Pseudomonas putida" as SB-bacteria detects the substance DNT (2,4-Dinitrotoluol). It was developed by the research team of Victor de Lorenzo to find anti-person-mines.
}

world" were noted mostly in connection with possible future applications (see examples above).

More than the possible risks, ethical aspects were named in the articles, like "frontiers of research" and questions like "What is life?", "Is man allowed to interfere in nature?" and "Shall man play god?"

Metaphors were employed to emphasize the potential risks and ethical aspects of the new scientific field of Synthetic Biology. But a deeper discussion of ethical and risk consequences did not really take place in the articles.

\section{Expert interviews}

The experts of the SB 3.0 conference in Zurich were also asked on the positive and negative sides of Synthetic Biology. Only four out of fifteen scientists talked explicitly of Synthetic Biology as a key opportunity to solve basic problems of the world, like for example Huib de Vriend: "We are facing big problems in this world with health, with the environment, with food production. They have to be solved somehow and that needs new technology. So this technology, we cannot afford to let it fail in any sense, not in a political sense at least, so something should be done about it." Or the biotechnologist Scott Moor "We need the scientific advances and the benefits certainly of things going the way we expect will far outweigh risks, but the risks are not zero."

The experts did not refer to positive opportunities only. Where they spoke about the positive effects and productivity caused by Synthetic Biology, 11 out of 15 experts also spoke about risks and the need for security measures. The majority of the scientists interviewed talked mostly about negative and feared consequences without explicitly mentioning positive opportunities. They also at the same time mentioned security measures against the risk of SBartefacts.

The biotechnologist Vitor A. P. Martins dos Santos for example said: "I think in every development, we always should have some inbuilt systems that would enable us to eliminate the harm the invention could generate. We should first try to prevent, but if it happens, we should try to have inbuilt systems that allow us to minimize this." Or also the American biotechnologist George M. Church, who stated that: "Everybody should get the readings (of DNA) so they can survey their environment to see what is going on. But they shouldn't be allowed to write (DNA) without a licence. The same way you don't want jet pilots to be any one person. They need a licence."

Only one biotechnologist refused to speak about security activities, because in his opinion biotechnology is in no way able to synthesize any harmful product yet. Phillipe Marlière: "Suppose that the community of synthetic biologists were asked to generate the most devastating 
biological agent to just get rid off the Amazonian forest. O.k.? We could not do it. Suppose Al Qaida would ask me and other people at the Pasteur Institute to create the ultimate infectious agent and so on. It would be extremely difficult to set up the protocol."

\section{The pictures of Synthetic Biology}

A short summary of these results will now show the general picture of SB drawn in the media and by scientists.

The media articles represented Synthetic Biology as a new scientific field of biology with an engineering-like way of thinking. The aims of genetic engineering were not clearly separated. Genetic components are to be used to build new organisms with utopian qualities, or that previously did not exist in nature.

Nearly every article used metaphors to explain Synthetic Biology, and also to tackle possible risks und ethical aspects.

The media articles only mentioned less concrete but mostly potential future applications, and it is a moot question whether they will be realized or are only promises.

The scientists interviewed mostly define Synthetic Biology as contrary to nature and the natural system. The majority of experts who work in a SB-laboratory also used metaphors to explain Synthetic Biology. The experts who observe Synthetic Biology explained the characteristics of Synthetic Biology nearly not with the help of metaphors.

The used metaphors attributed a mechanical and industrial meaning to the character and the visionary applications of Synthetic Biology by using references like for example to the car, to the infant play LEGO, to the ink jet printer, to the mobile phone or to the historical rise of the internet. A slight masculine gendering of the metaphors can be attested as the mechanistic and industrial references present analogies to cultural artefacts, which women mostly use or consume and men mostly use too, but also create and repair. The experts interviewed reflect more the risks than the opportunities of Synthetic Biology. The alleged security activities range from international conventions to national jurisdiction and organisational sanctions for laboratory research.

\section{Discussion}

A comparison of the American and European press analyses revealed that there is no established international consensus on the definition of Synthetic Biology (Pauwels and Ifrim 2008). The following discussion will show what is similar and what is different in the pictures of Synthetic Biology drawn in the media and by the scientists.
Definitions of Synthetic Biology

Our results show that the representation of Synthetic Biology in the media and the presentation of Synthetic Biology by SB-experts have in common the fact that the new, scientific character of Synthetic Biology is based in its new work-culture, which integrates engineering aims and methods into bioscience. Engineering relies on constructive and productive aims. The productivity of Synthetic Biology relies on the shaping and designing of organic, "natural" entities.

The scientists interviewed mostly define Synthetic Biology as contrary to nature and the natural system. The "not-natural" aspect used by scientists is not as overemphasised in the media.

Metaphors and phrases were often used to describe and illustrate abstract terms and subjects. By using these linguistic "pictures" the journalists and the experts try to explain Synthetic Biology and their applications and get the topic across to the recipients. “(...) metaphors make extremely complicated molecular processes intelligible (...) there is a correlation between the complexity of the phenomena and our dependency on metaphorical language" (Chew and Laubichler 2003).

The use of metaphors within the media articles and the experts was slightly different. Nearly every article needed metaphors to explain Synthetic Biology. The majority of experts who work in a SB-laboratory also used metaphors to explain Synthetic Biology. Only experts who observe Synthetic Biology very rarely explained the character of Synthetic Biology with the help of metaphors.

The metaphors themselves did not differ in their content from mechanistic and industrial semantics, like the car or LEGO. The main difference was between metaphorical phrases in the media articles and the interviews, which attributed creative and religious semantics to the aims of Synthetic Biology. Experts did not speak of their religious or divine role, of recreating the world. The character of Synthetic Biology was not at all defined by religious, creative (life giving) metaphors by the experts, but $1 / 3$ of the articles mentioned metaphoric language with religious references.

Artefacts and applications of Synthetic Biology

The media and the observing scientists speak less of specific innovations already created and more of the expectations that the commercial profit will increase with the increasing possibility of creating "unnatural" and artificial natural products. The paradigm shift of biology itself is defined by its turn from an analytical, "unproductive" science to a synthetic, "productive" science that also brings about economic prosperity. 
Opportunities and risks of Synthetic Biology

Though potential risks and especially ethical concerns have been mentioned, in a large part of the media articles the positive aspects of Synthetic Biology and their opportunities prevail.

On the other hand, the scientists are aware of the potential risks and demand appropriate safety measures. Reflected to the media article, the opportunities were mentioned less frequently by the scientists.

The majority of articles in the media present Synthetic Biology broadly with positive potentials. Discussions of the risks and also ethical concerns appear only very marginally in the media. In contrast, the experts interviewed reflect more the risks than the opportunities of Synthetic Biology. The alleged security measures range from international conventions to national jurisdiction and organisational sanctions for laboratory research.

\section{Conclusion}

To launch a new scientific field, like Synthetic Biology, in the public mind, an attempt is made to establish a connection to well known fields in everyday life. For this reason, and especially in order to describe and illustrate the abstract terms and subjects, use was often made of metaphors and phrases.

The metaphorical language in the representative media and the expert interviews pictures the new character of Synthetic Biology mostly by means of mechanistic and industrial metaphors. The experts and the media did not use any metaphors concerned with everyday artefacts like cosmetics, baby bottles, knitting or cooking. The metaphors refer only to experiences which are traditionally more those of masculine professions than of feminine, and to masculine symbolisms. Synthetic Biology's metaphors do not refer to cooking or pregnancy, which are traditionally activities and experiences connected with femininity. As the metaphors contribute a meaning to the complexity and newness of Synthetic Biology the mechanistic and industrial attributions could be a misleading "causal force" (Keller-Fox 2002). Not only the "absence of any foreseeable route to a clarification" (Keller-Fox 2002 , p. 132) but also the attribution of "personhood" into the new molecular possibilities, "that we are doing it at all. This process could ultimately have the most disturbing social consequences" (Martin 1991, p. 501). Disturbing in a way that the mechanistic and industrial metaphors give the impression that the creation of live by the Synthetic Biology technologies end up in artefacts, which are as easy to control as a car or an inkjet printer. Boldt, Müller and Maio even describe, that the technical metaphors change living organisms into dead things (Boldt et al. 2009, p. 56). The presented metaphors, which we found in the media articles and expert interviews don't intend to represent every metaphor ever used for the explanation of Synthetic Biology. We only see a tendency that the valuation of Synthetic Biology by metaphorical language is occupied with mechanical and industrial references, which could reduce the means and potential of living organisms.

The less discussion and examination of the potential risks may be due to less information about what really could happen. Synthetic Biology is more a future vision and nobody knows exactly what will come true. It is a little surprising that scientists are so critical of their work. This does not fit with the media and the general public image of scientists who do not seem to care about the consequences of their research results. When the biotechnologists referred to risk representations of Synthetic Biology within the media, the reference was only used as an example to show the overestimations of Synthetic Biology. A scientist brought this very clear to the point when he said very ironically that even if a terrorist were to order "smallpox as a biological weapon at a Synthetic Biology laboratory, it would not possible to synthesize it."

Several parameters influence the message on its way from scientists via the media to the public, and create different images and ideas in the mind. The sense of information can change on its way from addressor to receptor. So it is very important to know how these processes of representation work and to find strategies to influence the results of these processes.

If principles of knowledge transfer for a realistic discourse between science and society about Synthetic Biology are to be established, it will be necessary to consider questions like "What kinds of values are transported by the metaphors used? What metaphors could be used in the context of Synthetic Biology but have not yet evolved in the media or in the expert interviews? Why are innovative technologies like Synthetic Biology mostly presented and advertised by masculine actors?" And finally why are scientists still confronted with the criticism of having a naive worldview, of being unwilling to see the damaging possibilities of their innovations? A picture which no longer seems to be correct, as our results showed.

Open Access This article is distributed under the terms of the Creative Commons Attribution Noncommercial License which permits any noncommercial use, distribution, and reproduction in any medium, provided the original author(s) and source are credited.

\section{References}

Boldt J, Müller O, Maio G (2009) Synthetische Biologie. EKAH, Bern 
Bourdieu P (1970) Zur Soziologie der symbolischen Formen. Suhrkamp, Frankfurt a. Main

Caputi J (1988) Seeing elephants: The myths of phallotechnology. Feminist Studies 14(3):490-491

Chew MK, Laubichler MD (2003) Natural enemies-metaphor or misconception? Science 301:1479-1482. doi:10.1126/science. $301.5639 .1479 \mathrm{c}$

Dahinden U (2006) Framing - eine integrative Methode der Massenkommunikation. UVK, Konstanz

Glaser BG, Strauss AL (1998) Grounded theory. Strategien qualitativer Forschung. Verlag Hans Huber, Bern

Hall S (1997) Representation—cultural representations and signifying practices. Sage, London

Hampel J, Pfenning U (1999) Einstellungen zur Gentechnik. In: Hampel J, Renn O (eds) Gentechnik in der Öffentlichkeit. Campus, Frankfurt
Hampel J, Renn O (1999) Gentechnik in der Öffentlichkeit. Campus, Frankfurt

Keller-Fox E (2002) Making sense of life. Harvard University Press, Harvard

Latour B (2002) Iconoclash. Gibt es eine Welt jenseits des Bilderkrieges?. Merve Verlag, Berlin

Martin E (1991) The egg and the sperm. J Women Cult Soc 16(3):501

Pauwels E, Ifrim I (2008) Trends in American and European press coverage of synthetic biology. Synthetic Biology Project, November 2008

TESSY (Towards an European Strategy for Synthetic Biology) (2008) http://www.tessy-europe.eu/ 